Special Issue of the 6th International Congress \& Exhibition (APMAS2016), Maslak, Istanbul, Turkey, June 1-3, 2016

\title{
Evaluation of Rheological Behaviour upon Recycling of an Ethylene Vinyl Acetate Copolymer by Means of Twin-Screw Extrusion Process
}

\author{
M. FAtih Ergin And I. Aydin* \\ Rheology Laboratory, Chemical Engineering Department, Faculty of Engineering, Istanbul University, \\ Avcilar Campus, Avcilar 34320, Istanbul, Turkey
}

\begin{abstract}
Recycling of many polymers has gained a spectacular importance mainly because of its environmental and economical benefits. Ethylene vinyl acetate is one of the thermoplastics used directly as a final product and indirectly as an additive within many other polymeric materials. There has been limited research work on recycling of polymers even though recycling in industry has shown a spectacular growth in the last decade. It is the aim of this study to investigate and to evaluate the rheological behaviour of an ethylene-vinyl acetate copolymer resin upon recycling. For this purpose, original ethylene vinyl acetate granules were processed five cycles by using a twinscrew extruder and their rheological analysis was performed by means of an AR-G2 rheometer (TA Instruments), with a parallel-plate geometry, under a steady state condition. It was found that the rheological measurements of copolymer ethylene vinyl acetate exhibited a shear thinning constitutive behavior, obeying Carreau-Yasuda rheological constitutive model. The changes in flow and oscillatory shear measurements under different processing conditions were also determined in detail and results are reported in the paper.
\end{abstract}

DOI: 10.12693/APhysPolA.131.542

PACS/topics: 47.85.md, 83.80.Sg, 47.57.Ng, 83.80.--k, 81.20.Hy

\section{Introduction}

The economical growth of the plastics industry has a significant influence on the world economy. Plastics industry is being used for the renewal of many products and technologies such as healthcare, aerospace, automotive, maritime, electronics or textile. These sectors easily find solutions to their problems due to plastic materials. In many applications plastic materials are preferred even in place of traditional resources. However, one major issue of the plastics is the recycling of polymeric materials in polymer technology. In 2012, 25.2 million tons of postconsumer plastics waste ended up in the waste upstream. $62 \%$ was recovered through recycling and energy recovery processes while $38 \%$ still went to landfill [1]. Many experts have done a lot of research on the recovery, using different polymeric materials $[2-6]$. While plastics are still preferred, one major issue is the recycling of polymeric materials in polymer technology, since it is important to control whether the recovered materials have the necessary properties, required for the reuse.

The main goal of this study is to investigate the possibility of re-using and workability of recycled polymer compared to its corresponding original form. It was expected that such data may contribute for the preparation of optimized processing conditions during recycling of the polymeric material. For this purpose, ethylene vinyl acetate was chosen, because it is one of the thermoplastics

*corresponding author; e-mail: i.aydin@istanbul.edu.tr used directly as a final product and indirectly as an additive within many other polymeric materials. The aging of polymer is modeled by five extrusion cycles, so that an identified rheological behavior is applied to all samples. Hence, the workability of recycled materials was also noted in current study.

\section{Materials and equipment}

The polymer used in this study was a commercial ethylene-vinyl acetate copolymer, EVA 40W (vinyl acetate content of $40 \%$, density of $0.965 \mathrm{~g} / \mathrm{cm}^{3}$, melting point of $47^{\circ} \mathrm{C}$, melt flow index (MFI) of $52 \mathrm{~g} / 10 \mathrm{~min}$ ) produced by DuPont, Belgium. Recycling has been simulated by means of a co-rotating twin-screw extruder (Mini Lab, Thermo Haake, Germany). The screw was operated at $100 \mathrm{rpm}$ and at the temperature value of $75^{\circ} \mathrm{C}$. The polymer was re-processed five times (see Fig. 1). Samples labeled as "0" and from "R1" to "R5" represent original and the processed polymers, respectively.
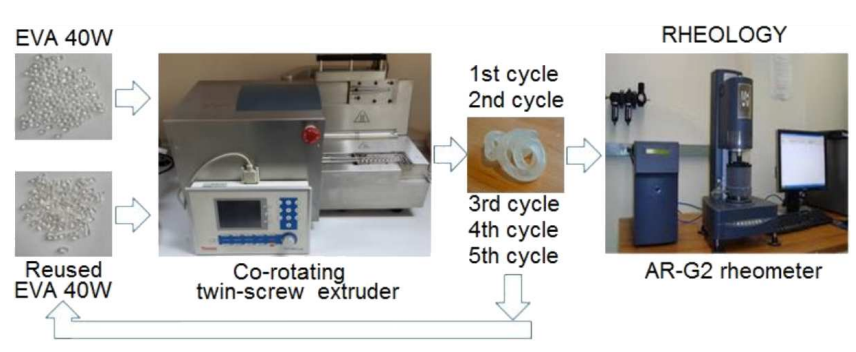

Fig. 1. Process flow of recycling of an ethylene vinyl acetate copolymer. 
Viscoelastic measurements of EVA $40 \mathrm{~W}$ melts were performed to investigate the change in rheological behavior of recycled polymers. A controlled stress rheometer (instrument model AR G2, TA Instruments, USA) equipped with a parallel plate (diameter equal to $25 \mathrm{~mm}$ and a constant gap value of $1000 \mu \mathrm{m}$ ) was used [7]. Test temperature value of $75^{\circ} \mathrm{C}$ and shear rate value of $0.1-100 \mathrm{~s}^{-1}$ were applied.

\section{Results and discussion}

Figure 2 shows the viscosity versus shear rate curves of EVA $40 \mathrm{~W}$ at $75^{\circ} \mathrm{C}$. This curve can be divided into three zones. In region I, named as newtonian region, shear rate value is low and the viscosity value is constant. Second region is a transition zone and the viscosity here decreases nonlinearly with decreasing shear rate. Region III is named as a shear-thinning region where the viscosity decreases with shear rate. To determine the power-law index, the slope of the viscosity versus shear rate is used in this region. In the shear-thinning region, the power law model is used to describe the relationship between viscosity and shear rate. The shear sensitivity of the polymer is expressed with power-law index. A smaller value of the power-law index indicates that the behavior of the polymer is more shear-thinning [8]. Figure 2 shows that effect of re-processing on polymer degradation is obvious, as the viscosity keeps decreasing upon increasing the number of recycling operations.

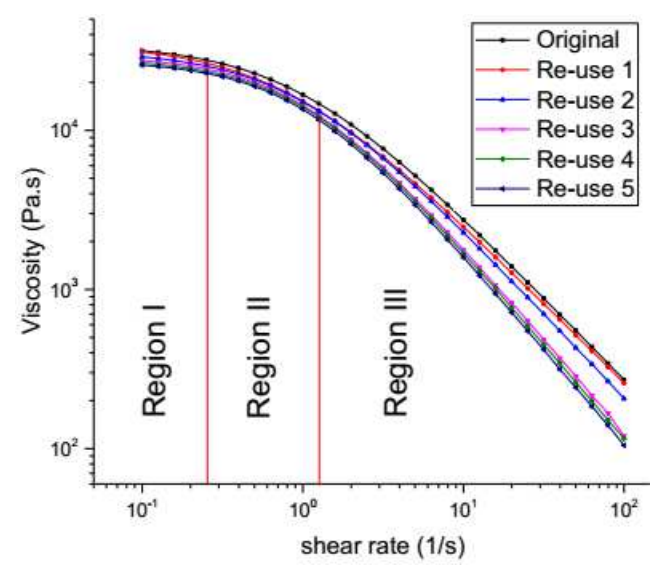

Fig. 2. Viscosity versus shear rate curves of EVA 40W at $75^{\circ} \mathrm{C}$.

Shear-thinning behaviour is observed when shear rate is increased (Fig. 2). In this experiment, the determined flow behaviour is in accordance the Carreau-Yassuda model of

$$
\lambda \frac{-\eta_{\infty}}{\eta_{0}-\eta_{\infty}}=\left[1+(\dot{\gamma})^{a}\right]^{(n-1) / a},
$$

where $\eta_{0}$ is the zero shear rate viscosity, $\eta_{\infty}$ is an infinite shear rate viscosity of the second newtonian plateau, $\lambda$ is a time constant, and $n$ is the power law index, which accounts for the shear thinning behavior. The parameter $a$ accounts for the width of the transition region between the zero shear viscosity and the power law region $[9,10]$.

The effect of processing can be easily related to a mechanical degradation of the polymer, whose molecular weight progressively decreases upon increasing the number of processing cycles. This is confirmed in Fig. 3, where the viscosity is plotted as a function of shear stress. The viscosity curves are all parallel, a behaviour which is typical for entangled polymer melts of varying molecular weight [11]. This indicates that the degradation after 1st and 2nd recycling steps is less effective, compared to 3rd, 4 th and 5 th recycling steps.

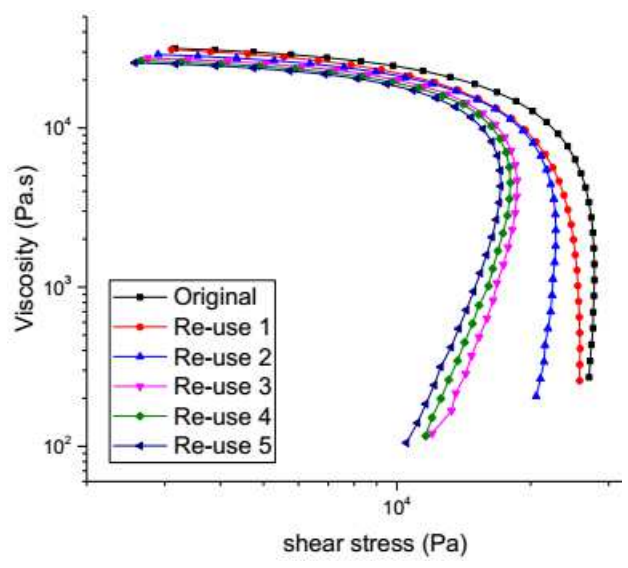

Fig. 3. Plot of viscosity versus shear stress of original and re-used EVA 40W.

Figures 4 and 5 show the values of the pseudo plastic behaviour and the viscosity of the material at the zero shear rates for EVA 40W. These data are important in enabling us to carry out an extrusion modelling on the reprocessed polymer.

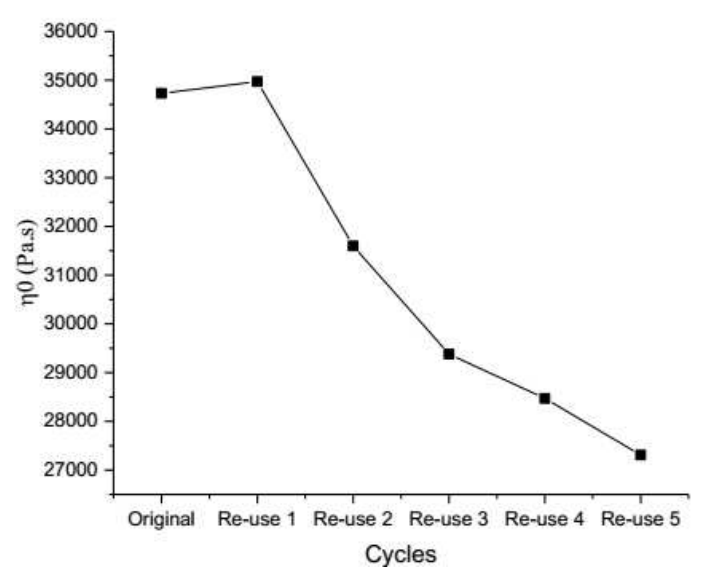

Fig. 4. Viscosity of original and re-used EVA $40 \mathrm{~W}$ at $100 \mathrm{rpm}$.

As it is seen in Fig. 4, original material shows higher viscosity than the re-used materials. Also each reused material experienced a decrease in viscosity after 


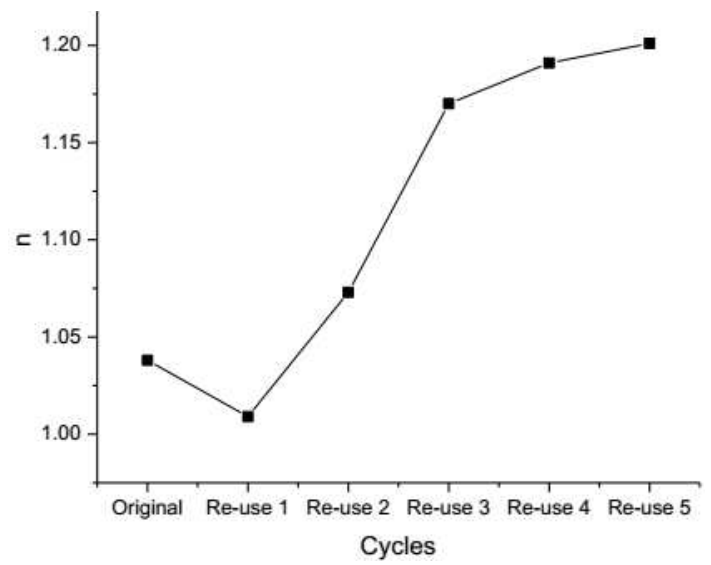

Fig. 5. Pseudo plastic behaviour of original and reused EVA $40 \mathrm{~W}$ at $100 \mathrm{rpm}$.

recycling in the same conditions $\left(75^{\circ} \mathrm{C}, 100 \mathrm{rpm}\right)$. This result may be related to variations in molecular weight. This difference results from a decrease in the molecular weight, which is originated from degradation of polymer because of breaks in EVA 40W chains (extruded and pelletized). This behavior is similar to that reported by other authors [12].

As depicted in Fig. 5, the change in the value of $n$ (pseudoplastic behavior of the material) increases with each increasing cycle. As a result, this increase in $n$, as may be seen in the trend of curve in Fig. 5, causes a reduction in the corresponding viscosity values.

\section{Conclusions}

In this study, the effects of recycling on EVA 40W was examined. Our study was focused especially on evaluation of the rheological properties of the material after repeating recycling. Regarding the rheological behavior, it was determined that the viscosity of the EVA $40 \mathrm{~W}$ decreases with each processing cycle. At the 4th cycle, at the shear rate value of $52.3 \mathrm{~s}^{-1}$, the viscosity falls by around $78 \%$. This difference results from the decrease in the molecular weight, which is originated from the degradation of polymer because of breaks in EVA $40 \mathrm{~W}$ chains.

One of the main goals of this study is to evaluate and obtain rheological data for using recycled materials instead of original material. In doing so, by using optimal and necessary process conditions, polymer material will be re-used many times. Hence negative effect of polymer material on the environment will be minimized and energy saving may be ensured.

\section{References}

[1] Plastics - the Facts 2014/2015. An analysis of European plastics production, demand and waste data, Associations of Plastics Manufactures, Brussels 2015.

[2] A. Ares, R. Bouza, S.G. Pardo, M.J. Abad, L. Barral, J. Polym. Environment 18, 318 (2010).

[3] J.E. Crespo, F. Parres, M.A. Peydró, R. Navarro, Polymer Eng. Sci. 53, 679 (2013).

[4] J. Datta, P. Kopczyńska, Crit. Rev. Env. Sci. Tech. 46, 905 (2016).

[5] M. García-Morales, P. Partal, F.J. Navarro, F. Martínez-Boza, C. Gallegos, Polymer Engi. Sci. 47, 181 (2007).

[6] E. Kuram, B. Ozcelik, F. Yilmaz, G. Timur, Z.M. Sahin, Polymer Compos. 35, 2074 (2014).

[7] M.F. Ergin, I. Aydin, Anadolu Univ. J. Sci. Technol.-A Appl. Sci. Eng. 16, 265 (2015).

[8] H. Eslami, Understanding Screw Design for Film Extrusion Process, 2014.

[9] P.J. Carreau, Ph.D. Thesis, University of WisconsinMadison, USA 1968.

[10] K. Yasuda, R.C. Armstrong, R.E. Cohen, Rheol. Acta 20, 163 (1981).

[11] J.D. Ferry, Viscoleastic Properties of Polymer, 3rd ed., John Wiley Sons, Chichester 1980.

[12] K.H. Su, J.-H. Lin, C.-C. Lin, J. Mater. Proc. Technol. 192-193, 532 (2007). 